\title{
Modern Türk Edebiyatında Dede Algısı
}

\section{Perception of Grandfather in Modern Turkish Literatüre}

\author{
Abdullah Harmanc1 a,* \\ ${ }^{a}$ Prof. Dr.; Necmettin Erbakan Üniversitesi, Sosyal ve Beşeri Bilimler Fakültesi, Türk Dili ve Edebiyatı Bölümü, \\ ORCID: https://orcid.org/0000-0001-9468-8595
}

\section{MAKALE BİLGİSİ}

\section{Makale Geçmişi:}

Başvuru tarihi: 14 Haziran 2020

Düzeltme tarihi: 18 Haziran 2020

Kabul tarihi: 23 Haziran 2020

\section{Anahtar Kelimeler:}

Modern Türk Edebiyat1,

Şiir,

Öykü,

Çocuk edebiyatı,

Dede.

\section{ARTICLE INFO}

Article history:

Received: June 14, 2020

Received in revised form: June 18, 2020

Accepted: June 23, 2020

\section{Keywords:}

Modern Turkish Literature,

Poetry,

Short story,

Children's literature,

Grandfather.
ÖZ

Dede, bir insanın hayatında, birçok farklı açından onu etkileyen bir faktördür. İnsan kendini bir sonuç olarak görmekteyse, dedenin birçok şeyin sebebi olduğunu düşünmek yanlış olmaz. İnsana ve onun hayatına böylesine büyük etkisi olan bir aktörün gene insan tarafından üretilen edebiyata farklı biçimlerde yansımaması düsünülemez. Modern Türk edebiyatında şiirden öyküye, romana ve çocuk edebiyatına uzanan birçok edebi türde ve alanda dedenin konu edildiği görülür. Modern hayat her şeyi değiştirdiği gibi dedeyi de değiştirir. Torunla dedenin arasındaki olumlu ilişkiler, modern hayatın zorunlulukları içerisinde değişir. Dede bazen değişimin konusu olmuş ve ailesinden uzaklaşmıştır. Dedesiz olmak, birçok yazının ve öykünün, şiirin konusu haline getirilmiştir. Makalede; yetişkin edebiyatında özellikle öykü ve şiir türlerinde, ayrıca çocuk edebiyatının farklı türlerinde dede figürünün nasıl ele alındığı sorusu cevaplandırılmaya çalışılacaktır.

\section{A B S T R A C T}

Grandfather is a factor that affects a person's life from different points of view. If a person considers himself as a result, it would not be wrong to think that the grandfather would be the cause of many things. It is unimaginable that an actor who has such a great impact on people and his life would not be reflected in the literature produced by humans in different ways. In modern Turkish literature, it is seen that the grandfather is mentioned in many literary genres and fields extending from poetry to short story, novel and children's literature.Modern life changes everything, as well as the grandfather. The positive relationships between grandchildren and grandparents change within the challenges of modern life. Grandfather was sometimes the matter of change and moved away from his family. Being without a grandfather has been the subject of many essays and short stories, poems. In the article, it will be attempted to answer the question of how the grandfather figure is mentioned in adults' literature, especially in the genres of short stories and poetry, as well as in different genres of children's literature.

\section{Giriş}

Aile bir toplum için ne kadar önemli bir kurumsa, aile için de önemi tartışılmaz bir unsur vardır: Dede. Dedelik, bir yandan "baba"lık anlamı içerirken ama öbür tarafiyla "baba"dan daha öte ve derin anlam ihtiva eden bir ferde dönüşür. Dede ile baba veya baba ile oğul arasında cereyan eden gerilimli ilişki, dede ile torun arasında adeta bir gönül

* Sorumlu yazar/Corresponding author

e-posta: abdullahharmanci1974@gmail.com dostluğu haline gelir. Baba ile çocuk arasındaki zaman zaman sertliğe dönüşen kurallar, ilkeler ortadan kalkar. Bu bir anlamda çocukluğun başındaki kişi ile çocukluğuna yeniden kavuşmuş kişi arasındaki bir ilişkidir.

Edebiyat, toplumu ve hayatı bir biçimde yansitır. İnsana ilişkin her türlü renklilik, hareketlilik edebiyata yansır. Dede gibi önemli bir aile ferdinin edebiyata yansımaması 
düşünülemez. Nitekim modern edebiyatımızda özellikle torununun gözünden anlatılan dedeler naif, kırılgan, hasbi, sevecen dedelerdir. Çocuk edebiyatı yazarlarının dede portrelerini daha çok ön plana aldıkları görülür. Zira çocuk edebiyat1 "çocuğa göre”lik dediğimiz bir kavram üzerinden inşa edilir ve çocuk hayata bakmaya başladığında çevresinde ilk gördüğü varlıklardan biri dededir. Üstelik bu göze ilk çarpan aile ferdi, diğerlerinden daha farklı bir bakışa veya konuma sahiptir. Adeta sorumlulukları baba eğlenceli eylemleri ise dede üzerine almış gibidir.

Dil üzerine çalışmalarıyla bildiğimiz İbrahim Demirci "dede" kelimesinin yapısına ve anlamına ilişkin olarak şunları söyler:

"Dede de aslinda bir baba, hem annenin babası hem babanın. Amca ile dayıyı, hala ile teyzeyi ayıran Türkçe, dedeleri ve nineleri ayırmamıș ama ninelerin "anneanne" ve "babaanne" olarak belirlenmeleri yine de bir ayrıcalık sayılabilir. "Babababa"mı, "annebaba"mı yok; dedelerimizi karıştırmamak için, "annemin babası", "babamın babası" dememiz gerekiyor. Buna da şükür! Fransızlar gibi "dede" yerine "büyük+baba", "nine" yerine "büyük+anne" demek zorunda kalabilirdik. Hoş, "dede"nin ve "nine"nin varlığına rağmen "büyükanne" ve "büyükbaba" diyenlerimiz de oldu. Olabilirdi. Oldu. Olsun!” (Erişim 1)

Modern edebiyatımızda dedeye nasıl bakıldığ 1 , dedenin nasıl görüldüğü, dedenin kim olduğu sorularını sorarak bir dede portresi çıkartmaya çalıştığımızda, yapabileceğimiz ilk belirleme, bu konuda yazılanların neredeyse tümüyle bir "torun bakışı"nı mündemiç olduğu yönündedir. Nasıl ki kadına yönelik belirlemeler, değerlendirmeler, genellikle erkeğin bakışını ortaya koyan bir denemeyse, dedeye bakıldığında da torunun bakışını görmüş oluruz. Dedeye bakan, "torun gözü" olduğu için / torun gözü olduğu zaman, bunun sonuçlarını tahmin etmek de zor olmayacaktır.

Modern edebiyatımızın metinleri, narin, ağırbaşlı, sevimli, anakronik, romantik, dindar bir dedeyi belirginleştirir. Belki buradaki narin ifadesi bazı portreleme denemeleri için pek mümkün gözükmez. Hoyrat bile olsa, dedeler, sevimlidir. İllaki içinden çıktıkları kültürün taşıyıcısıdırlar. Folklorik bir bilgi hazinesidirler. Doğal hayatın "pir"idirler. Öğreticidirler. Bilgedirler. Esasında bir kültürün içinden çıkmış değildirler. Bir kültürün içinde kalmıştırlar. Yaşadıkları zamana kendi zamanlarını taşırlar. $\mathrm{Bu}$ onları anakronik yapar. Dede, kendinden önceki zamanların birikimini kendinden sonraki zamanların dağarcığına eklemek için durmadan anlatır ve dinletir.

Edebi metinlere yansıyan bu portrenin neden böyle şekillenmiş olabileceği sorulabilir. En kestirmeden söylenecek söz, edebi metinlerde böyle bir portre vardır, zira hayatta da gerçekten böyle bir dede profilinden bahsedilebilir, olacaktır. "Böyle olduğu için böyle gözükür." denecektir. Bakan gözün varlığını yadsıyan, bakan kişinin kendine mahsus yanılsamalarını önemsemeyen bu görüş, yaratıcı öznenin katkısını, etkisini görmeyerek elbette yanılmaktadır. Nitekim hayatın olağan değişimi, dinamizmi, dede portrelerini de değiştirir.
Ezberlerimizi bozar. Ancak bu ezber bozucu yaklaşımlar da ilhamını hayattan almaktadır. Anlatanın ne kadar anlattığı, nereden ve nasıl anlattığı problemi bir tarafa, Geber Anne! başlıklı romanların yazıldığını hatırlayacak olursak, sadece anlatılanlar değil anlatanlar da değişmektedir.

Köksal Alver, dedeyi genetik bir figür olan yönüyle ele alır. İnsana dünyadaki yolculuğunda yön verecek olan birçok unsur aslında dededen babaya babadan oğula veya kıza geçmiştir. Bu duRuma ilişkin olarak şunları ifade eder.

"Dede, genetik bir aktör, genetik bir öncüdür. İnsanın hem biyolojik hem de sosyolojik genetiğinin belirleyici aktörlerinden biridir. İnsan, dedesinden getirdikleriyle hayata dahil olur, ondan aldıklarına kendini katarak hayatı yeniden yorumlar. Bir yönüyle insan dedelerine bağlı olup dedelerinin kendi zamanına uzanmıs izidir. İnsanın kendini bir şekilde dedeye bağlamak istemesi, dedesizliği neredeyse yabanlık ve yalnızlık dahası bir köksüzlük olarak görmesi anlamlıdır. Dede sanki insanı bu dünya hayatına sağlam bir şekilde bağlayan bir tutamaktır" (Erişim 2).

Nazan Bekiroğlu'nun baba ile oğul arasındaki ilişkiyi deşifre eden yazısında (Bekiroğlu, 2005: 179-198) belirttiği gibi, baba ile oğul ilişkisi daha çok bir iktidar, güç çatışmasıyla açıklanabilir. Baba henüz iktidarını kaybetmemişken, oğul iktidara ulaşmıştır. İşte bu tehlikeli dönemeçte baba - oğul arasında gerilimli bir ilişki ortaya çıkar. Baba otoritesini kullanmak ve yitirmemek derdinde iken, oğul bu otorite altında bulunmaktan memnun değildir. Herhangi bir biçimde bu otoriteyi sarsmanın, bazen göz göze gelmeyerek, bazen susarak, bazen kabullenmiş görünerek otoritenin manyetik alanından mümkün olduğunca daha az etkilenmenin yollarını arar.

Baba - oğul ilişkisini böylesine gerilimli ve sorunlu hale getiren "yakınlık”tır. Dede - torun ilişkisini ise dünyadaki her insanın çok daha farklı tanımlayacağına şüphemiz yoktur. İşte bu farklılaşmanın sebebi de sanırım, iki çocuğun karşılaşmasıdır. Evet, dede ve torunun karşılaşması, iki çocuğun karşılaşmasıdır. Her şeyi bilen bir çocukla, hiçbir şeyi bilmeyen bir çocuk karşılaşırlar. İşin kötü tarafı, bu çocuklardan birinin vakti azalmıştır. Zamanı dolmak üzeredir. Özellikle modern toplumda, baba olmanın yaşının ne kadar yükseldiğini hatırlayacak olursak, artık dede ile torun arkadaşlığı epeyce kısalmıştır. Bunun doğal bir sonucu olarak, dedeler, hem de biz henüz çocukluktan çıkmamışken, bize ölümü öğreterek giderler. Biz en hassas, en masum, en cahil çağımızda, ölümle karşılaştığımızda, bu acıklı olayın kahramanı dedemiz ya da ninemizdir. Hayatın faniliğini, geçiciliğimizi, ölüm diye bir gerçeğin olduğunu ve çocukluk masalını bitiren dönemecin genellikle bu gerçek olduğunu anlarız. İki çocuktan biri öldügünde, geriye önünde koskoca bir hayat duran diğer çocuk kalır. Mahzun ve yalnızdır. İşte edebi metinlere yansıyan dede portreleri biraz da bu sebeple kırılgan, acıklı, yenilgiyi tatmış portrelerdir.

Dede bize ölümü öğreterek giderken, edebiyat ürünlerimiz dede ölümleriyle dolup taşar. Dede fanidir ve bize faniliği belletir. Dedenin evi terk edilir, yıkılır, boşaltılır, 
başkalarına devredilir. Babanın ölümü şehzadeye bir taht hediye ederken, dedenin ölümü torunu saltanatından eder. Torunluk öyle bir saltanattır ki, esasında modern edebi metinler, bu saltanat senelerini tüketip tahtını kaybeden sultanın iç geçirişlerinden ibarettir. "Dünyada torunluğun ne aziz bir saltanat olduğunu bilmeyen var mıdır? Torun olmak, büyük babaların, büyükannelerin, elbebek gülbebek sevgisiyle büyümek, derim ki, şu kısacık, doyulmaz hayatın en tatlı, en lezzetli duygusu olmalı." diyen Turan Karataş (2007: 21) bu saltanata dikkat çeker.

Dede hakkında edebiyatımızda üretilen metinlerin, zihnimizde oluşmuş genel dede portresine paralel olanlarla bu portreyi zorlayanlar ya da bu portrenin rağmına bir tasvir içine girenler şeklinde iki grupta incelenmesi söz konusu olabilir. Bazen dedeler, belki de babanın bulunmadığı ortamlarda can sıkıcı bir otoriteye dönüşebilirler. Ya da her zaman kendisine gönülden bağlanılan bir şahıs olmaktan çıkıp daha soğuk ve daha sıradan çizilebilirler. Belki de sıradan kelimesini zıddıyla değiştirmek gerekir. Modern dünyanın dedeleri bildiğimiz dede portresinin dişına çıkarlar. Kendilerini gençleştirmenin yollarını ararlar (Türkoğlu, 2007). Bu sıradışı, alışılmadık dede anlatımlarına gelmeden önce, zihnimizde teşekkül etmiş dede portrelerini örnekleyen edebi metinlere kısaca bakalım.

\section{Torun Bakışı}

Dede, genellikle çocuk edebiyatının değerli bir figürüne dönüşmüştür. Modern edebiyatımızın geniş bir kolu olan çocuk edebiyatımız içerisinde dede portrelerine sıkça rastlanır. Çocuk edebiyatı doğal olarak çocuğun bakışına odaklanır. Çocuğun bakışı ise kendisine en munis gelen figürleri öne alır.

Cahit Zarifoğlu'nun Yürek Dede ile Padişah adlı eseri "tipik" denebilecek bir dede portresi ile karşı karşıya bırakır bizi. Tipiktir zira edebiyatımızın dede figürlerine yüklediği bütün olumlu özellikler söz konusudur Yürek Dede'de. Eserin farklı tarafı dedemizin torun ile karşılaşmamasıdır. Tek başına portrelenir. İdealize edilmiştir. Oldukça sevecen, iyi niyetli, olumlu bir tiplemedir. Konuyla ilgili araştırmasında Vural Kaya şu yorumları yapar:

"Yürek Hasan Dede ile Ayşe Nine'nin öyküsüdür Yürekdede ile Padişah masalı iki ihtiyarın mütevazı hayatlarının anlatıldığı hikâye geleneksel değerlere en fazla gönderme yapan masalıdır Zarifoğlu'nun. Günümüz dünyasının göremeyeceği bir dünyayı çocukların gözleri önüne sermekle ise başlıyor yazar. Tam anlamıyla Zarifoğlu, Yürekdede ile Padişah’ta, değerler bütününü bir masal ile sıralayabilmiş, onları kullanılabilir bir tertiple yeniden modern dünyanın imkanına sunmuş ve çocuğun dikkatiyle buluşturabilmiştir, diyebiliriz. Yürekdede dünyada kanaatin, ahlakın, nezaket ve kıymet bilirliğin, iyilikseverliğin, yardım severliğin, dost oluşun, tevazuunun, izzet ve ikramlılı̆̆ın temsil kişisidir Hasan Dede. Etrafına bir ışık gibi saçılmaktadır. Hayatı huzur ve mutluluğun ama kanaatle elde edilebilmiş bir mutluluğun özetidir." (Kaya, 2007: 20)
Hüseyin Kaya'nın "İlk Arkadaşım” adlı çocuk romanında da aynı şekilde (Kaya, 2013) genel bir dede portresinin bütün ipuçları bulunabilir. Dede arkadaştır. Birlikte oyun oynanır. Dede, öküzlerine kendi azığındaki salatalıkları yedirir. Bu, dedenin de bir çocuk olduğunu gösteren güzel bir örnektir. Dede, doğadaki tüm bitkilerin isimlerini bilir. Dede, pek çok halk şairinin şiirlerini ezbere bilir. Şifahi kültüre sahiptir. Her şeyden önemlisi, dede zaman dışıdır. Ayların ve mevsimlerin isimlerini kullanmaz. Ekin biçme, harman kaldırma, koyunların kuzulama zamanı gibi ifadelerle yıl takvimini kendince adlandırır. Dede, belli bir zaman sonra ölecek ve yukarıda ifade ettiğimiz gibi, hayatın hakikatinden bihaber torununa ölümü de öğreterek gidecektir. Zira dedenin bir vasfı da bilgeliği ve öğreticiliğidir.

Çocuk edebiyatımızın son senelerde ön plana çıkan Sevim Ak'ın Gemici Dedem adlı çocuk romanı modern zamanların dedelerini portrelemesi açısından ilgi çekicidir. Zira öyküyü bizi aktaran çocuk dedesini tanımamaktadır. Onunla bir kış günü karşılaşır. Ancak karşısındakinin dedesi olduğunu bilmez. "Markette benim seçtiklerimi torbalardan çıkarmaya çalışırken kap1 çaldı. Kap1 gözünden baktım, saçı başı birbirine girmiş, yüzünde derin çizgileriyle bir adam soğumuş ellerini ovuşturuyor." (Ak, 2018: 13) Çocuğun gözünden betimlenen bu yaşlı adam anlatıcımızın dedesidir. Geçmiş zamanda, babası ile dedesi arasında çeşitli anlaşmazlıklar olmuş ve ikisinin yolları ayrılmıştır. $\mathrm{Bu}$ ayrılığın çok uzun sürdüğünün torunun dedesini tanımamasından anlayabiliriz. Sevim Ak'ın ilginç hikayesinde, her gün torun ile dede birbirlerine biraz daha yaklaşacaklardır. Ancak torun bu yaşlı adamın gerçekte kim olduğunu zamanla anlar. Dedesi olmayan bir çocuğun bile bir şekilde bu ihtiyacını hiç tanımadığı ama şefkat dolu bir ihtiyarla karşılaması ilginçtir. Sonradan bu ihtiyarın dedesi olduğunu fark etmesi ortadaki gerçeği değiştirmez: Çocuk tıpkı bir babaya ihtiyaç duyar gibi bir de dedeye ihtiyaç duymaktadır.

Hüseyin Su'nun "Yanağımda Dedemin Sakal İzleri" öyküsü (Su, 1998: 35-48), dedeliğin en bariz özelliklerinden olan "sakal"ı başlığına taşıması ve dedenin torununa muhabbetini sergilemesi açısından son derece etkileyici bir metindir. Söz konusu olan büyük ailedir. Dolayısıyla, öyküyü baştanbaşa saran neşe havası, biraz da “torun-anlatıcı"nın yakın akrabalarla çevrili bir hayat sürüyor olmasındandır. Öykü, dedelerin, torunlarının her türlü hal ve hareketlerini meşrulaştırıcı bir üst otorite olmalarını da örnekler. Babalar, genellikle çocuklarının şımartılmasından gizli gizli rahatsız olurlar. Ancak kendi babalarına söz geçiremezler. Torun, dedesinin koltukları arasında bütün davranışlarına bir meşruiyet kazandırır. "Yanağında Dedemin Sakal İzleri", daha çok bir ramazan ayı öyküsüdür. Oraya odaklanılmıştır. Ancak ramazanın tadı daha çok çocuklukta, çocukluğun tadı ise dede ve ninelerin sağladıkları güven ve huzur ortamında neşvünema bulur. Böylelikle dede ile ramazanı birleştirir. $\mathrm{Bu}$ iki bileşen torunla buluştuğunda okurun damağına uhrevi bir lezzet uğrar. İşte öyküyü sarmalayan bu uhrevi lezzet ancak böyle izah edilebilir. Hem çocukluğun hem de ramazan ayının iki cihanı da saran saadeti... 
Esra Köse'nin "Dedem, Çocuklar ve Akrepler" şiiri de (Köse, 2013: 23), bilindik dede portresinin desteğinde yazılmıştır. $\mathrm{Bu}$ şiirde, dedelerin anakronik oluşları, kendine mahsus bir kişiliğe sahip oluşları gibi durumların altı çizilir. "Dedem bilmez saati akrebi yelkovanı / Bildiği tek akrep dostları, öyle der / Zamanında çok sokulmuş aynı delikten / ... / Vakitlerini göğe bakıp anlayan dedem. / Cübbesinin altına giydiği lastik ayakkabılarından asla vazgeçmeyen adam sakallıdır"... Burada altı çizilen durum, dedenin zaman algısının ve kıyafetlerinin, bilindik çizginin dişında olmasıdır. Lastik ayakkabı ve cübbe giyer. Zamanı belirlemek için saat yerine gökyüzünü kullanır.

Numan Altuğ Öksüz'ün "Dedemin Yaş”” öyküsü, dede hakkında yazılmış edebi metinlerin çok büyük bir bölümü gibi, dedeyi ölümüyle anlatır. Kendisine bir çocuk-arkadaş gibi bağlanılan dede, bir gün aniden ölür ve torun bu ölümü kabullenemez. "Dedemin adını taşıyan tek torunuyum. Bundan midır bilmem dedem benimle çok ilgilenirdi." (Öksüz, 2019: 32) cümleleriyle başlayan öykü, aslında alttan alta dedelerin gözünde her torunun aynı ilgiyi ve sevgiyi görmediği, torunlar arasında bir sevgi hiyerarşisi olduğunu düşünmemize yol açar. Elbette ilk olmak veya tek olmak veya dedenin ismini taşıma bir toruna neden daha fazla değer verildiğini açıklar. Dedelerin daha çok masal ve hikâye anlatmalarıyla ön plana çıkmaları alışıldık bir durumdur. Numan Altuğ da dedesinin bu yönünü öne çıkartır: "Harika bir anlatıcıydı dedem. Alçalıp yükselen sesi, bazı hecelerin üstündeki vurguları, mimiklerini ve ellerini kullanması beni hikâyelerin derinliklerine doğru yolculuklara çıkarırdı." (Öksüz, 2019: 32)

Köksal Alver'in "Dut Ağacı Boyunca" (2011: 41-46) öyküsü "İdris dede öldü” leit-motifiyle örülüdür. İdris dede, çocuklarla ilgilenen, onlara Kuran öğreten ideal bir tip olarak görülür. Burada kan bağıyla bağlı olunan bir deden ziyade, belli bir mahallenin çocuklarına sahip çıkan bir pir-i fani kast edilir. "Dede" metinlerinin önemli bir bölümünde, dedelerin idealleştirildiği vakidir. Romantik ve ideal bir dede figürü, edebi metinlere yansıyan portrenin en azından büyük bir bölümünü içerir.

Alver'in dede kavramını ele alış biçimi bizim kültürümüze özgü bir duruma işaret eder. Burada "dede" şeklinde anılan kişi kan bağıyla bağlanılan bir dede değildir. Ancak bilindiği gibi, bizim kültürümüzde, kan bağı olmasa da, yaş almış insanlara "dede, teyze, hala" gibi ifadelerle hitap edilir. Alver de bu uygulamayı örneklemektedir. İnsanlara iyilik yapan bir "pir-i fani”" şeklinde yüceltilerek portrelenen kişi ile ancak insani ve gönülden bir bağ kurulabilir.

Dede ve ölüm izleklerini bir araya getiren metinler arasında İbrahim Tenekeci'nin "Dedeler ve Çiviler" şiiri öne çıkar (1997: 32). Bir torunun dedesinin seneler önce gerçekleşmiş ölümünü anlattığı şiirde, dedenin "tabutunun her şeyi ikiye bölerek ilerlemesi”, dedenin ölümünün torunun hayatında açtı̆̆ı yarayı anlatır. Şiir ayrıca çoğu torun için dedenin duvarda bir fotoğraftan ibaret oluşunun ilginç bir tanıklığıdır. İki çocuktan biri yalnız ve mahzun kalmıştır:

\section{“yă̆mur yă̆lyor}

yüzlerce ırmağa dönüşüyor cam

ve rahmetlinin remi için

duvara çivi çaklyor babam” (Tenekeci, 1997: 32)

Şair İlhan İlikçioğlu'nun konuyla ilgili şiiri, dedesine tanık olmadan büyümüş çocukların ortak hislerini yansıtması bakından önemlidir. Zira birçok farklı sebepten dolayı torun ile dedenin karşılaşması ihtimali azalmıştır. Modern hayat evliliği geciktirdikçe dede torun ilişkisinin süresi de kısalır. Veya başka sebeplerden bazı torunlar dede tanıklığını hiç yaşamazlar. Çocukluklarını dede merhametinden uzakta geçiren büyüklerin bu eksikliklerinin ne gibi olumsuz sonuçlar verdiği sorusu psikologlar için kuşkusuz önemli araştırma alanıdır. Şair İlikçioğlu'nun şiiri bu duruma 1şı tutar:

Dedem ben doğmadan ölmüş.

Isterdim $\mathrm{ki}$;

Ak saçlı,

Ak sakallı,

Yüzü nurlu bir dedem olsun.

Ama olmadl.

Gözümde kaldl.

Dedem ben doğmadan ölmüş.

Isterdim ki;

Torunlarını başına toplasın.

Başlarımızı okşasın.

İbretlik hikâyeler anlatsın.

Ama olmadl.

Gözümde kaldı. (Erişim 3).

Dede, varlığıyla da yokluğuyla da çocuk üzerinde bir etki unsurudur. Onsuz olmak, çocuk muhayyilesinde bir eksikliğe işarettir. Şair Ömer Korkmaz da dedesizliğin sonuçları üzerine yazdığı deneme yazısında şöyle der:

"Dedesizliğin anlaşılabilmesi için insanın çocukluktan biraz uzaklaşması, belki ilk gençlik çağına yaklaşması gerekiyor. Galiba bende de tastamam böyle oldu. Bir şeyin varlığından habersizseniz yokluğunun sizi kavrayıp kuşatması gibi bir şey söz konusu olmuyor. Bir dedeye sahip olmanın verdiği ayrıcalıkları gözlemlemek için yaşadığım sosyal çevrede bana tesir edecek, gözüme batacak bir şey olmamıştı ve dedesizliğimi hissedememiştim. Ancak, yaşım ilerleyip yeni bir takım çevrelerle hemhal olmaya başlayınca ve yeni hayatlar görünce dede olgusunu hissetmeye başladım. İlkokul yıllarım aynı zamanda ilk verileri topladığım zamanlar olmuştu" (Erişim 4).

Dedesizliğin değil ama bir bakıma babasızlığın sancılarını çeken ve anılarında dedesine sıkça vurgu yapan Necip Fazıl'ın "Bir Yalnızlık Gecesinin Vehimleri" (Necip Fazıl, 2007: 7-14) öyküsü, dedenin ölümünü hüzünle ele almayan, bunun dramatik yönüne vurgu yapmayan ender metinlerdendir. Burada öykücünün peşinde olduğu şey, "başkasının ölümüne" karşı beslenen esrarengiz merak duygusudur. Bir çocuk için bir ölü beden görmek, metafizik âlemle ilgili birtakım sırların kilidini çözmek gibi de algilanabilir. 
Necip Fazıl, dedesinin yitirmenin acısından ziyade ölüm gerçeğine yaklaşmış olmanın ürpertisini duyar. Birçok anı kitabında dedesine olan sevgisini aşikâr eden Necip Fazıl'ın böylesi bir kurmaca metinde otobiyografik özellikler kullanması öykünün gücünü artıran bir özelliktir. Öyküde geçen şu satırlar, dedesine duyduğu sevgiden ziyade yazar çocukluğunda ölümün esrarengiz atmosferine beslediği hayret duygusunu örnekler:

"Büyük babamın ölüsünü hamama koymuşlardı. İşte halamın oğluyla beraber ölüyü görmek için bahçeye çıktık ve hamamın yüksek penceresine bir merdiven dayayarak içeriye göz attık. Çocuk merakı... Büyükbabam, teneşirde upuzun yatıyordu. Göz açıp kapayıncaya kadar baktığım ölüden bana çarpan şey, yalnız sakalları; sapsarı derisinin üstünde tane tane yapıştırılmış gibi duran seyrek ve beyaz sakalı oldu. Ölü bir tenden fişkıran, kurumuş otlar gibi ölü ve kıvırcık teller..." (Necip Fazıl, 2007: 11)

Dedeyle ilgili metinlerde hep görülen bir başka husus onun sürekli "anlattığı"dır. Anlatmayı, konuşmayı, aktarmayı çok sever. Aslında kendi zamanından getirdiği bilgi, görgü, tarih yükünü ancak bu suretle kendisinden sonrakilere ulaştırabilir. Yaşlanmak bilgeleşmeyi, bilgeleşmek de çocuk ve torunlara bu bilgi ve hikmet dağarcığını aktarmayı zorunlu kılar. Yaşlanan kişilerin çok daha fazla konuştukları çoğu zaman evlatlar tarafından şikâyet makamında olsa da dile getirilir.

Buraya kadar çizdiğimiz dede portresinin genel temayüle uygun örneklerden seçildiğini belirtelim. Ancak dede anlatımları her zaman bu genel portreyi destekler mahiyette değildir.

Yılmaz Yılmaz'ın "Yakınımız Irak Oldu” öyküsü, dede ile torun arasındaki anlaşmazlıkları, çatışmayı örnekler. Geleneksel, dini bir hayat yaşayan ve torunundan da böyle bir hayat yaşamasını bekleyen dede, onun tercihlerini anlayamaz ve üzülür. Torun geceleri çalışmakta, gündüzleri uyumaktadır. Dede ise gündüzün rızık için gecenin ise dinlenmek için olduğunu vurgular ve berekete ulaşmanın yolunun gündüzleri uyumamayı gerektirdiğini belirtir. Burada ilginç olan iki neslin zaman algılarının değişmiş olmasıdır. Ayrıca torunun öğrenmeyi tercih ettiği müzik aleti de dedenin durumu yadırgamasına sebep olur. Burada dede ve torun, bir yaşama biçimi noktasında anlaşamamaktadırlar. Torunun çocukluktan çıkıp gençlik çağına girmiş olması, Yılmaz Yılmaz'ın öyküsünü diğer dede metinlerinden ayırır. Daha doğrusu, öyküdeki çatışmanın bir sebebi de, torunun büyümüş olması, çocuk olmamasidır.

Dede - torun çatışmasını örnekleyen bir metin de Zeynep Delav'a aittir (2018: 39-43). Delav, son derece otoriter, baskıcı, anlayışsız bir dede portresi çizer. Torunlarının gözünden çizilen bu portredeki dede, onların radyo dinlemesine izin vermez. Kendisinden korkulur. Çekinilir. Onun eve gelmesi torunlarda büyük bir telaşa sebep olur. Burada dededen ziyade baba otoritesini andıran bir kişi söz konusudur: "Tülay garip bir hisle, kapı ile radyonun aynı anda kapandığını anladı. Ödü koptu, korku içinde ablasına bağırd1. 'Ablaaaa!' Dedeleri öyle bir öfkeyle 'Gelin ulan buraya!' demişti ki, anneanne bile soluğu torunlarının yanında aldı. İçeri girdiklerinde dedelerinin sürekli yutkunduğunu görünce radyo tiyatrosunu ...unutuverdiler ama şimdi bunu dedelerine nasıl ispat edeceklerdi?" (Delav, 2018: 43)

Buraya kadar anlamaya ve çözümlemeye çalıştığımız edebi metinlerin bir torun bakışını içermesi söz konusuydu. Oysa zaman zaman "dede"lerin de torunlarına nasıl baktığı meselesi, öykü ya da şiirlere yansımıştır.

“Dede bakışı”nı örneklemesi açısından, Akif Paşa'nın ölen torunu için yazdığ $\breve{1}_{1}$ çok içli bir şiir olan "Mersiye"den bahsetmek gerekir. 1845 yılında vefat eden Akif Paşa, bilindiği gibi, "Adem Kasidesi" ile modern şiirimize önderlik etmiş önemli bir isimdir. İşte bu Akif Paşa'nın kaybettiği torunu için yazdığı "Mersiye"si şöyledir:

"Tifl-ı nâzenînim unutmam seni

Aylar günler değil geçse de yıllar

Telh-kâm eyledi firâkın beni

Çıkar mı hâtırdan o tatlı diller

Klyılamaz iken öpmeğe tenin

Şimdi ne hâldedir nâzik bedenin

Andıkça gülşende gonca-dehenin

Yansın âhım ile kül olsun güller

Tagayyürler gelip cism-i semine

Döküldü mü siyâh ebrû cebîne

Sırma saçlar yayıldı mı zemîne

Dă̆ıldı mı kokladı̆̆ım sünbüller

Feleğin kînesi yerin buldu mu

Gül yană̆ın reng-i rûyun soldu mu

Acaba çürüdü toprak oldu mu

Öpüp ohşadığım o pamuk eller” (Kutlu, 1981: 332-333)

Necati Mert'in Zamansız (2011: 9-28) adlı öykü kitabına aldığ 1 ilk dört öykü, torunu Dubai'de yaşayan bir dedenin torun özlemini dile getirir. Uzun süre torununu göremeyen, görse bile çok kısa zamanlar içinde gören bir dedenin torun özlemini onun doğum günü videolarını izleyerek dindirmeye çalışması ise son derece çarpıcı bir sahnedir. Burada, hem toruna dedenin nasıl baktığını hem de modern dünyada artık dedelerle torunların bir arada yaşamalarının ne şekilde kısıtlandığını görmek mümkün olmaktadır.

Aynı yazarın Fincan Fincanla (Mert, 2020: 11-55) adlı öykü kitabında da "Koydan Ötesi Deniz" başlıklı öyküler serisi içinde çok geleneksel bir dede figürünü barındırır. Tenekecilere gelin giden Ayfer Çetin adlı bir çocuk doğurur ve Çetin dedesinin ve babasının aynı çatı altında yaşadıkları bir evde yetişir. Çetin'in babası kendi babasıyla bazı sorunlar yaşarken, kendisi de zamanla babasına karşı gelecektir. Dede - baba - torun üçlüsü aynı evdedirler ve öyküde zaman zaman anlatıcılık yapan Çetin'in uzun seneler boyunca olup bitenleri aksettirmesi kaleme getirilir. 
Modern dünya, dedelerle torunları ayırmakla kalmamış, dedeleri "dede"likten çıkarmaya başlamıştır. Bundan sonra yapılacak bir dede incelemesi, bu "tuhaf dede"yi ya da "alış1lmadık dede"yi önemsemelidir. Said Türkoğlu'na ait şu satırlar (2007: 12) değişen dede portresini eleştirir: "Bir de modern zamanların dedeleri vardır. Dedelik yaşına geldikleri halde kendilerine dedelik hiç yakışmayan dedeler. Gençlik dönemlerini uzatmak telaşına düştükçe sevimsizleșen dünya delileri. Seküler dedeler, zamanı durdurmak isterler. Öte beklentileri bir nitelik kazanmadığından dünyaya yapıştıkça yapışırlar. Gençlere benzemek, genç görünmek çabaları kendilerini gülünç duruma düşürür." Türkoğlu'nun belirlemeleri sosyal hayatımıza denk düşmekle birlikte, bir taraftan da ağır ve anlamaya çalışmayan bir eleştiriyi bünyesinde barındırır.

\section{Sonuç}

Ailenin önemli bir figürü olan dede, çocuk üzerinde çok fazla etkilidir. Dede bir bakıma hayatta başladığı yere geri dönmüştür ve çocuk için bütün bir hayatın özünü temsil eder. Dedenin dönüp dolaşıp geldiği yer esasında çocuğun olduğu yerdir. Bitirmek başladığımız yere geri denmektir.

Metafizik olana, hayret duygusuna açık olan çocuk, dedesinde, hayata ve evrene ilişkin meraklarını bulur. Hayatın ona sunacaklarının neler olacağını tahayyül etmesini sağlar. Dede figürü babaya oranla ailede çok daha serbest bir rol oynar. Adeta babanın sorumluluklarını değil de eğlenceli yönlerini almıştır. Baba ile oğul arasında yaşanan gerilim veya çatışma, dede ile torun arasında yaşanmaz. Dede, çocuğun eğlenceye, oyuna, hayatın sevecen taraflarına açılan kapısı gibidir.

Dede portresinin edebiyatımıza yansıyan yüzü elbette bu yazıda incelenmeye çalışıldığı kadar değildir. Tarandığında bunların dışında pek çok dede metni bulunabilir. Ayrıca bu inceleme bize şunu göstermiştir ki, çocuk edebiyatı alanı dede portresinin yansımalarını incelemeye çok daha elverişlidir.

$\mathrm{Bu}$ yazıda üstünde durulamayan roman türünde canlandırılan dede portreleri başlı başına bir araştırmayı gerektirir. Ancak edebiyatımızda dede profilini işleyen örnekleri artırmak her zaman bu konuya dair yeni durumlar keşfedeceğimiz anlamına gelmez. Çoğunlukla, bilinen durumların çoğaltılması söz konusudur.

Edebiyatımızın çizdiği genel dede profili belli başlı özellikleri üstünde barındırır: Sevecen, bilge, ağırbaşlı, şefkatli, cömert, sabırlı, hikaye anlatıcısı vs. Sosyal hayatımızın değişimi, edebiyatımızdaki "dede" profilinin de değişmesine yol açmıştır. Ancak her şey gibi dede portresi de modern hayatta kendine mahsus değişiklikler geçirir. Bu değişim genellikle olumsuzdur. Zira modern hayat dedelerle torunların arasını açar. Onların aynı evlerde yaşamalarına engel olur. Dede ile torunun birlikte geçirdikleri süreyi eksiltir. Dede işlediğimiz bazı metinlerde öncelikle bir yabancıdır. Dedesiyle karşılaşıp onu tanımayan torunlara rastlanır. Bu durumun sorumlusu elbette torun değil, baba ile oğul arasında, yani torunun babası ile dedesi arasında geçmişte yaşananlardır.

Necati Mert öykülerinden bahsederken altını çizdiğimiz gibi, dede - torun ilişkileri de hayatımızdaki yabancılaşmaya paralel olarak değişmekte, ilişki biçimi, bir arada yaşayan ve bu birlikteliğin tadını çıkartan "iki çocuk"tan, birbirine ulaşamayan ve birbirini sürekli özleyen "iki çocuğa" evrilmektedir.

\section{Kaynakça}

Ak, S. (2018). Gemici dedem. Can Çocuk Yay.

Alver, K.. (2007). Çevgen, Hece Yay.

Bekiroğlu, N., (2005). Cümle kapısı. Timaş Yay.

Delav, Z., (2018). Kemik tozu. Hep Kitap Yay.

Karataş, T. (2007). Ne Torun Oldum, Ne Dede, Sühan dergisi. (16). 21.

Kaya, H., (2013). Ilk arkadaşım, Zambak Yay.

Kaya, V., (2007). Cahit Zarifoğlu'nun Çocuk Kitaplarında Temel Değerler, (Basılmamış Yüksek Lisans Tezi), Selçuk Üniversitesi, Konya.

Köse, E., (2013). Dedem, çocuklar ve akrepler, Yedi İklim dergisi, (284). 23.

Kutlu, Ş., (1981). Tanzimat Dönemi Türk Edebiyatı Antolojisi, Remzi Yay.

Mert, N., (2011). Zamansız, Hece Yay.

Mert, N., (2002). Fincan fincanla, Şule Yay.

Necip Fazıl, (2007). Hikâyelerim, BD Yay., 2007.

Öksüz, N. A., (2019). Ellerim neden siyah?, Ötüken Yay.

Su, H., (1998). Gülşefdeli yemeni, Hece Yay.

Tenekeci, İ, (1997). Üç köpük, Dergah Yay.

Türkoğlu, S., (2007). "Dedem Öldü, Koptu Zembereği Çocukluğumun”, Sühan dergisi, (16). 12.

Yılmaz, Y., Yakınımız ırak oldu, yayımlanmamış bir öykü.

\section{Elektronik Kaynak}

Erişim 3: https://www.liseedebiyat.com/rler/173-t-ilebaslayanlar/tasnif-disi/13125-dede-siirleri.html (13.06.2020)

Erişim 2: https://www.hayatedebiyat.com/koksal-alverdede-imgesi/ (13.06.2020)

Erişim 4: http://www.hayatedebiyat.com/omer-korkmazdedesizlik/ (13.06.2020)

Erişim 1: http://www.hayatedebiyat.com/ibrahim-demircidede-demek-ne-demek/ (13.06.2020) 


\section{Extended Abstract}

Our modern Turkish literature has come a long way until today by shaping from the middle of the 19th century. A large number of works have been given in the genres of poetry, short stories, novels, plays, essays, and so on. The characteristic of literature to include life and society entirely allows us to follow many events and details that we see in our society through these literary works. Social and individual changes and transformations can be read via literary texts in our modern literature. In a sense, literature serves as a "mirror" to life and society. It is possible to have knowledge of a period or a society by examining literary texts. Several studies have been carried out on how the family, the most important element of society, is reflected in literature. In this article, even if he is not the head of the family or nuclear family, the question of how "dede" (elder-grandfather), who has a great spiritual gravity, took place in literary texts was wondered. The similar aspects of the grandfather portraits in these texts were tried to be understood by choosing certain texts such as poems, stories, and novels. When the grandfather entered the lens of literature, it was naturally determined that the eye looking through this lens is generally the gaze of the grandchildren. The grandfather, the important figure of the family, is very influential on the child. In a sense, the grandfather has come full circle where he started in life and represented the essence of the whole life for the child. The point where the grandfather has come full circle is the point where the child is. Finishing is to go back to the point where we started. The child, who is open to metaphysical things and has a sense of wonder, finds his curiosity about life and the universe in his grandfather. It allows him to imagine what life has to offer him. The grandfather figure plays a much more liberal role in the family than the father Grandfather almost took the fun aspects of the father, but not the responsibilities. The tension or conflict between father and son does not happen between grandfather and grandchild. Grandfather is like a child's door to fun, play, and the affectionate side of life. It may be possible to examine the texts produced in our literature about Grandfather in two groups as those that are parallel to the general grandfather portrait formed in our minds, those that force this portrait, or those that are depicted in contrast to this portrait. Sometimes grandparents can become an annoying authority, perhaps in the absence of the father. When we try to draw a portrait of a grandfather by asking the questions of how the grandfather is looked at in our modern literature, how the grandfather seems, and who the grandfather is, the first determination we can make is that the "grandchild's gaze" is hidden almost entirely in what is written on this subject. Just as determinations and evaluations about women are generally an essay that reveals the view of men, when we look at the grandfather, we see the gaze of the grandchild.
Since it is the "grandchild's eye"/when it is the grandchild's eye looking at the grandfather, it will not be difficult to predict the consequences. The texts of our modern literature concretize a delicate, dignified, charming, anachronic, romantic, religious grandfather. Perhaps the delicate expression here seems unlikely for some portraying attempts. Although the grandfather are rude, they are cute. They are necessarily the carriers of the culture they came from. They are a wealth of folkloric knowledge. They are the "pir" (sheikh) of natural life. They are instructive. They are wise. They actually did not come out of a culture. They are stuck in a culture and carry their own era to the eras they live in. This makes them anachronic. Grandfather continuously tells and makes them listen to the experience of the times before him to add to the knowledge of the times after him. In this context, the following works have been emphasized: : Sevim Ak, Gemici dedem, Köksal Alver, Çevgen, Nazan Bekiroğlu, Cümle kapısı, Zeynep Delav, Kemik tozu, Turan Karataş, Ne Torun Oldum, Ne Dede, Hüseyin Kaya, Illk arkadaşım, Necati Mert, Zamansız, Necati Mert, Fincan fincanla, Necip Fazıl, Hikâyelerim, Numan Altuğ Öksüz, Ellerim neden siyah?, Hüseyin $\mathrm{Su}$, Gülşefdeli yemeni, İbrahim Tenekeci, $\ddot{U}_{c ̧}$ köpük...The change in our social life has also caused the change in the profile of "grandfather" in our literature. Just like everything else, the portrait of a grandfather also undergoes specific changes in modern life. This change is usually unfavourable, because modern life drives a wedge between grandparents and grandchildren. It prevents them from living in the same house. It reduces the time spent by the grandfather and grandchild together. The breakdown of families or the narrowing of the communication of modern family life, called extended family, naturally drives a wedge between the grandfathers and the grandchildren. The contact or less contact of family members prevented the grandfather from being involved in the grandchild's life as intensely as in our old family lives. It influenced the development of individuals negatively. It is also understandable that we come across more children's literature texts when examining grandfather figures. Because the main objective of children's literature is to reflect the child's point of view and suggest a figure who looks at life as a child. When you choose your narrator or your point of view from the children, you will see that family members such as mother, father, grandfather, grandmother are at the forefront of the figures that will reflect more from his eyes. Our text of children's literature should be studied only in the context of grandfather figures, and this should be carried to the wider scientific studies rather than article size. As a suggestion to our article, we stated that Turkish children's literature texts should be examined in terms of the child figures they contain. 